\title{
AFINAL, DESENVOLVIMENTO REGIONAL SERVE PARA QUÊ? REFLEXÕES A PARTIR DA SOCIOLOGIA DA \\ LIBERTAÇÃO DE FALS BORDA E DA SOCIOLOGIA DA EXPLORAÇÃO DE CASANOVA
}

\author{
AFTER ALL, REGIONAL DEVELOPMENT MAKES TO WHAT? \\ REFLECTIONS FROM SOCIOLOGY OF LIBERATION BY FALS \\ BORDA AND FROM SOCIOLOGY OF EXPLOITATION BY \\ CASANOVA
}

\author{
Luciana Butzke \\ Universidade Regional de Blumenau - Blumenau - SC - Brasil \\ Oklinger Mantovaneli Júnior \\ Universidade Regional de Blumenau - Blumenau - SC - Brasil \\ Ivo Marcos Theis \\ Universidade Regional de Blumenau - Blumenau - SC - Brasil
}

\begin{abstract}
Resumo: A história, tanto do desenvolvimento quanto da teoria social na América Latina, está imersa no paradigma eurocêntrico, no encobrimento do Outro (maiorias exploradas no subcontinente), na exploração da natureza e na predominância de discursos "desde fora". A teoria do desenvolvimento regional, considerada de médio alcance, é derivada da teoria do desenvolvimento e traz, em sua bagagem, enfoques importados que prometem milagres ao levar o progresso às regiões subdesenvolvidas da periferia. A teoria social, no geral, e a sociologia-centro, em particular, são parte desse paradigma e desse discurso. Nesse sentido, trazemos neste artigo a sociologia-periferia, de Fals Borda e de Casanova, em diálogo com a questão regional, como possibilidade de contra-discurso. Essa sociologia abriga a crítica eurocêntrica da teoria social e do desenvolvimento que teve lugar na América Latina, e discute o compromisso da ciência no pensar com a região e no agir para transformar/libertar a região.
\end{abstract}

Palavras-chave: Desenvolvimento Regional. Teoria Social. Sociologia. América Latina. Pablo Gonzalez Casanova. Orlando Fals Borda.

Abstract: Both the history of development and the history of social theory in Latin America are
immersed in the Eurocentric paradigm, in covering up the "other" (the great majority exploited in
the subcontinent), in the exploitation of nature and in the predominance of speeches from outside.
The theory of regional development, a medium range theory, derives from the theory of
development, and brings imported approaches that promise progress to the underdeveloped
regions of the periphery. Social theory, in general, and the social theory of the European core, in
particular, are parts if this paradigm and this speech. In this sense, we bring in this article the
peripheral sociology of Orlando Fals Borda and Pablo González Casanova in dialog with the
regional question as possibility of a counter-speech. This sociology contains the criticism of both
the Eurocentric social theory and the development process took place in Latin America by
discussing the commitment of science in "thinking with the region" and "acting to transform/free
the region". Keywords: Regional development. Social theory. Sociology. Latin America. Pablo Gonzalez Casanova. Orlando Fals Borda. 


\section{Introdução}

A preocupação com o desenvolvimento não é nova. Remonta ao processo de constituição das Ciências Sociais e da Sociologia, embora o debate em torno do desenvolvimento ainda não se colocasse no século XIX. A reflexão sociológica do século XIX e início do século XX limitava-se, geograficamente, à Europa e aos Estados Unidos, preocupando-se com a transição de organizações sociais tradicionais para organizações sociais tidas como modernas (ESCOBAR, 2007; OQUENDO, 2004).

A teoria do desenvolvimento vai se constituir na medida em que experts e políticos começaram a ver como problemáticas certas condições da Ásia, da África e da América Latina - a pobreza e o atraso econômico, por exemplo. O discurso do desenvolvimento e do subdesenvolvimento foi elaborado e disseminado pelos Estados Unidos e pela Europa ocidental. Mas, aos poucos, o desenvolvimento foi se convertendo num tema central também "no" e "para" o Terceiro Mundo (ESTEVA, 2000).

A genealogia da teoria do desenvolvimento e a história da teoria social na América Latina estão intrinsecamente ligadas. Nesse sentido, a análise da história da sociologia latino-americana deve ser considerada a partir de uma dupla perspectiva. Por um lado, é preciso considerar seu estreito vínculo com a história econômica, social e política. Por outro, é necessário ter em conta a lógica de desenvolvimento da ciência, que incluí o estudo de teorias formuladas no estrangeiro e a existência de preocupações e suposições nascidas da reflexão autóctone (LEÓN, 2004).

No campo da teoria do desenvolvimento, área de conhecimento predominantemente interdisciplinar, destacam-se, entre as décadas de $1950 \mathrm{e}$ 1970, a teoria da modernização (GERMANI, 2010), o estruturalismo cepalino (BIELSCHOWSKY, 2000) e a análise da dependência (BRESSER-PEREIRA, 2010; CARDOSO, 1993; CHILCOTE, 1983). Nas décadas de 1980 e 1990, ganham audiência os enfoques neo-institucionalista e neoliberal (BERTONCELO, 2011) e, mais recentemente, as perspectivas do pós-estruturalismo, pós-colonialismo, pósdesenvolvimentismo e as teorias feministas de desenvolvimento (ESCOBAR, 2007; PEET; HARTWICK, 2015). Vários cientistas sociais se debruçaram sobre o tema do desenvolvimento, contribuindo para os enfoques citados, encontrando-se consolidado o aporte destes para a teoria do desenvolvimento.

O propósito deste artigo foi mapear as interfaces entre a teoria do desenvolvimento e a teoria social, mas com ênfase na contribuição de sociólogos que, em geral, não se encontram entre os que figuram nos enfoques mais conhecidos da teoria do desenvolvimento, a saber: Orlando Fals Borda, com a contribuição da sociologia da libertação (FALS BORDA, 1970), e Pablo González Casanova, com a proposição de uma sociologia da exploração (CASANOVA, 2009a). O mapeamento proposto visou identificar elementos nessa sociologia que se pensa ao mesmo tempo que pensa a América Latina - e trazê-los para o debate, procurando incorporar novas contribuições à teoria do desenvolvimento e, em especial, à teoria do desenvolvimento regional. Convém ressaltar que partimos da concepção de desenvolvimento e de região que os autores aqui em consideração apresentam. De forma que o mapeamento realizado parte da concepção de desenvolvimento e de região que os autores trazem em seus textos, 
que não necessariamente coincide com aquela usual em estudos sobre o desenvolvimento regional - que toma região por uma escala subnacional.

O artigo está estruturado em sete partes, incluindo esta introdução. A segunda parte aborda o eurocentrismo presente nos estudos sobre teoria social e teoria do desenvolvimento. Na terceira parte é apresentada a metodologia utilizada no estudo dos autores e suas obras. Na quarta parte abordam-se vida e obra de Fals Borda e Casanova. A quinta parte traz os principais elementos da sociologia da libertação e da sociologia da exploração. A sexta parte trata dos autores em sua relação com o desenvolvimento regional. E, por fim, na sétima e última parte, são delineadas algumas considerações finais.

\section{0 eurocentrismo nos estudos sobre teoria social e teoria do desenvolvimento}

Antes de a "modernidade" estabelecer-se, os etnocentrismos (chinês, asteca, hindu ou muçulmano) eram regionais. O primeiro etnocentrismo mundial foi o europeu. A particularidade europeia transformou-se no mundo por excelência, e o mundo dos Outros se tornou inferior. A partir de 1492, com a descoberta da América e a vitória sobre os árabes, a Europa foi se tornando o centro do mundo. A Europa passou de periferia do mundo muçulmano a polo irradiador de cultura ao mundo: uma particularidade tornou-se universalidade (DUSSEL, 2012; THEIS, 2015).

A América não foi "descoberta" como algo novo, mas como aquilo que o europeu pode inventar a sua imagem e semelhança: Com efeito, "a América não é descoberta como algo que resiste distinta, como o Outro, mas como a matéria onde é projetado o "si mesmo". Então, não é o "aparecimento do Outro", mas a "projeção do si mesmo": o encobrimento." (DUSSEL, 1993, p. 35).

A história, que se sucedeu à "descoberta" da América, passou a ser articulada em múltiplos espaços e tempos estruturalmente desiguais e heterogêneos, configurando com todos eles uma mesma e única ordem mundial. Trata-se de uma estrutura que vem se desenvolvendo na América Latina há mais de 500 anos, sustentando-se e se reproduzindo a partir da desintegração dos padrões de poder existentes, absorvendo e redefinindo aqueles poderes úteis ou necessários à reprodução do capital (QUIJANO, 2000).

O debate sobre desenvolvimento/subdesenvolvimento é posterior à Segunda Guerra Mundial e representou a reconfiguração do poder capitalista neste período. A ideia dominante era que o desenvolvimento consistia em uma questão dos países e regiões, não referida a um dado padrão de poder. Esse debate foi praticado dentro de um padrão eurocêntrico de conhecimento que, desde o Século XVIII, é um dos instrumentos principais do poder capitalista (AMIN, 1989).

Que as ciências sociais construídas na Europa e nos Estados Unidos durante o século XIX fossem eurocêntricas não deve surpreender. A teoria da modernização difundiu a tese de que existe um caminho modernizante comum para todos os povos/nações/áreas, mas eles se encontram em etapas diferentes nesse caminho. O desenvolvimento passou a ser definido como o processo pelo qual um país avança por um caminho universal da modernização (WALLERSTEIN, 2006). 
A tensão entre o universal e o particular na teoria social e na teoria do desenvolvimento foi, e continua sendo, objeto de debates acalorados. O universalismo tem sido atacado como uma forma de particularismo disfarçado e bastante opressivo. Mas, também podemos considerar que universalismo e particularismo não são opostos. Nesse sentido, a reflexão sobre a América Latina abre a possibilidade do universalismo pluralista, considerando que não pode haver "Outro", porque o "Outro" é parte de nós mesmos. Em síntese: só um universalismo pluralista nos permitirá captar a riqueza das realidades sociais em que vivemos e temos vivido (DUSSEL, 1993; WALLERSTEIN, 2006). E é nessa direção que se insere o esforço de reflexão aqui proposto.

\section{A dialética e a analética aplicada aos autores e suas obras}

A tensão entre o universalismo eurocêntrico (particularismo disfarçado) e o universalismo pluralista se mostra presente na obra de Fals Borda e Casanova. A ideia, neste artigo, foi a de trazer o debate sobre o universal e o particular, tão caro nas discussões sobre o pensamento social latino-americano, aos autores e suas obras.

Para tanto, foram selecionados dois textos para esse artigo: Es possible una sociología de la liberación? de 1968 (FALS BORDA, 1970) e Sociología de la explotación de 1969 (CASANOVA, 2006a). A tentativa foi a de situá-los em um contexto mais amplo, nomeadamente, no da discussão sobre teoria social e desenvolvimento, tendo como ponto de partida e de chegada a América Latina. Alguns outros textos foram mobilizados para suprir lacunas, mas não houve a intenção de descrever e analisar toda a obra dos autores.

O método dialético, do romeno Lucien Goldmann, em diálogo com o método analético do argentino Enrique Dussel, ajudou no processo de leitura e análise dos autores e de suas obras. Essa combinação pode ser considerada adequada porque rompe com a ideia de verdade e do pensamento como algo individual, explicado pela biografia do autor. A obra acaba sendo reflexo coletivo e tendo sua importância transcendendo o indivíduo que a criou (GOLDMANN, 1967).

O pressuposto de que parte o método dialético é de que o conhecimento nunca está acabado. Em estudos de autores e suas obras, o pensamento é apenas um aspecto parcial do ser humano vivo e inteiro. O sujeito que observa e reflete sobre a sociedade faz parte dessa sociedade. A compreensão de uma obra (tomem-se, aqui, as obras dos autores ora considerados) remete ao entendimento do significado imanente dos "objetos" de estudo. A explicação da obra implica inseri-la em uma estrutura mais ampla, na qual ela passa a ser um elemento. Observar o lugar que estes objetos particulares, limitados, ocupam dentro de uma estrutura mais ampla, contribui para explicar seu papel, sua natureza, as razões de sua existência (LÖWY, 2016). 
Dessa forma, consideramos as particularidades de Fals Borda e Casanova, mas também buscamos pontos comuns. A busca do universalismo pluralista nos permite captar a riqueza das realidades sociais em que vivemos e temos vivido (WALLERSTEIN, 2006). O avanço na reformulação latino-americana de uma certa visão de totalidade, implica ir da dialética para o momento analético proposto por Dussel. O momento analético:

Es superación de la totalidad desde la trascendentalidad interna o la exterioridad, el que nunca ha estado dentro. Afirmar la exterioridad es realizar lo imposible para el sistema (no había potencia para ello); es realizar lo nuevo, lo imprevisible para la totalidad, lo que surge desde la libertad incondicionada, revolucionaria, inovadora. (DUSSEL, 1996, p. 187-188).

Considerando que "a marcha do conhecimento aparece (...) como uma perpétua oscilação entre as partes e o todo, que se devem esclarecer mutuamente" (GOLDMANN, 1967, p. 6), o momento analético traria o pluralismo como afirmação da exterioridade latino-americana.

\section{A sociologia nos contextos e vidas de Fals Borda e Casanova}

Orlando Fals Borda nasceu em Barranquilla, Colômbia, em 1925 e faleceu em 2008. Sua família era presbiteriana e ele manteve, durante toda a sua vida, uma íntima relação com a religião. Passou pela Escola Militar de Cadetes e teve a oportunidade de estudar nos Estados Unidos, custeado pela igreja. Seus estudos tinham como tema principal a literatura e a música. O contato com a Sociologia viria apenas no último semestre de estudo. De volta à Colômbia, logo passou a se identificar como sociólogo, indo trabalhar na Winston Brothers Company, companhia norte-americana que construía represas. Por conta de um relatório sobre a região onde trabalhava, a companhia resolveu subsidiar seu mestrado em sociologia em Minesota. Sua dissertação de mestrado foi sobre os camponeses dos Andes e, no doutorado, fez uma tese sobre o homem e a terra em Bogotá. Em 1961, criou com Camilo Torres e María Cristina Salazar a Faculdade de Sociología em Bogotá (FARFÁN; GUSMÁN, 2012).

Pablo González Casanova nasceu em Toluca, Estado do México em 1922. Fez licenciatura em Direito, mestrado em História, em 1947, e se doutorou em Sociologia, em 1950, com uma tese, orientada por Fernando Braudel, sobre sociologia do conhecimento na América Espanhola. Foi o primeiro doutor em ciências sociais do México. Ele teve um papel chave na profissionalização da sociologia no México. Em 1972 assumiu a reitoria da Universidade Nacional do México - UNAM, transformando-a numa universidade aberta e democrática. No período de 1950 a 1969, entre a Guerra Fria e a Revolução Cubana, ele firmou seu compromisso anti-imperialista. Mais recentemente, com a queda do muro de Berlin, a insurreição zapatista, de 1994, e a destruição das torres gêmeas em 2001, que marcam o nascimento do capitalismo totalitário, Casanova inova com os conceitos de colonialismo global, exploração global e um projeto de democracia universal (ROSENMANN, 2009). 
A obra de ambos, Fals Borda e Casanova, é ampla. Fals Borda tratou de temas como a história e a cultura regional, teoria e prática social, investigação participativa e ordenamento territorial (FARFÁN; GUSMÁN, 2012). Casanova, por sua vez, tratou das relações sociais de exploração, do colonialismo, da luta por democracia e do desenvolvimento (ROSENMANN, 2009). A preocupação principal de ambos foi e é a de refletir sobre a realidade latino-americana e tratar o conhecimento sociológico como instrumento de transformação na busca de desenvolvimento político, econômico e social para as maiorias exploradas no subcontinente (ameríndios, negros, mestiços, mulheres, camponeses, trabalhadores urbanos, excluídos etc).

\section{0 desenvolvimento da sociologia-periferia}

Ao longo das décadas de 1960 e 1970, Fals Borda e Casanova começaram a denunciar o colonialismo intelectual, tanto das direitas quanto das esquerdas, junto com Aníbal Quijano, Enrique Dussel, Arturo Escobar, Edgardo Lander e Boaventura de Sousa Santos, contestando o "para que" do conhecimento em seu entorno específico.

Nesse contexto, Fals Borda escreveu em 1968 o texto Es possible una sociología de la liberación?, publicado na coletânea Ciencia propia y colonialismo intelectual, de 1970. Aí ele trata das incongruências da chamada ciência universal aprendida no Norte e aplicada ao nosso contexto regional. Fals Borda não nega a universalidade da ciência, mas indica que é preciso chegar nela a partir da originalidade das realidades locais. Os países subdesenvolvidos devem dar os passos na direção de uma ciência própria e libertar-se da ciência e tecnologia da metrópole imperialista, que deformam a cultura e aumentam a dependência. Essa ciência própria é uma ciência militante e destinada ao povo, cuja objetividade precisa combinar estudo e ação (FALS BORDA, 1970; FARFÁN; GUSMÁN, 2012).

Para concretizar essa ciência própria, militante, é necessário investir em duas linhas de ação: a primeira é estimular a dissidência dentro das instituições de ensino superior dos países avançados e a segunda é criar escolas de ensino superior independentes na periferia, a fim de diminuir o servilismo e o colonialismo intelectual, sem cair na xenofobia. A ciência deve estar a serviço dos direitos humanos fundamentais e da criação de formas autênticas de democracia econômica, social e política. Estas são fundamentais para o desenvolvimento autônomo dos países da América Latina, bem como para a reorganização das universidades numa perspectiva latino-americana. A sociologia da libertação é, na sua essência, uma "sociologia regional" (FALS BORDA, 1979; 1970).

Casanova, por sua vez, escreveu, em 1969, o texto Sociología de la explotación. Nele confirma a incompatibilidade entre democracia e exploração, vinculando método, conhecimento e alternativa ao desenvolvimento com novas formas de pensar e atuar em ciências sociais. A sociologia da exploração nasce da crítica da sociologia da modernização e da sociologia do poder (que tem como maior exemplo a teoria da dependência) (ROSENMANN, 2009). O embate é com os marxistas deterministas, que profetizavam a morte do sistema, e com os dependentistas, que não consideravam a lei do valor e a exploração como 
importantes para explicar o que ocorre na periferia do mundo (CASANOVA, 2006a) ${ }^{1}$.

Para os dependentistas, a assimetria está ligada à ideia de poder e domínio. Nesse contexto, para Casanova (2006a), é a exploração que deveria ser a categoria mais importante da análise e a dependência entraria como consequência da exploração. A desigualdade, o poder e o desenvolvimento fazem parte da relação de exploração, bem como a igualdade, a liberdade e o progresso.

\begin{abstract}
Las relaciones de fuerza y poder - la liberdad y falta de liberdad - no aparecen (...) como fenómenos naturales, o individuales o metafísicos, sino como fenómenos históricos ligados a la relación social de explotación entre propietarios y desposeídos; el progreso tampoco aparece como fenómeno natural o individual o metafísico, sino como un fenómeno vinculado a la relación de explotación, a las clases que a lo largo de la historia se benefician de él, se lo arrebatan. (CASANOVA, 2006a, p. 38).
\end{abstract}

A sociologia da exploração tem como objetivo teórico e metodológico a tarefa de contextualizar a famosa fórmula da mais valia, no sistema mundo capitalista e nas regiões periféricas e coloniais. A exploração colonial pode ser compreendida como exploração de uma região, de uma nação ou de um conjunto de habitantes (comunidade, tribos) que se encontram sob o domínio imperialista. Isso não impede que sejam feitas alianças das classes dominantes nativas com as classes dominantes do imperialismo, e que ambas se unam para realizar no interior das colônias a exploração combinada - que se intensifica com a discriminação racial e cultural.

$\mathrm{Na}$ superação da exploração combinada, é preciso ir além dos fatores e atores que estão a serviço do modo de produção capitalista. A luta essencial é pela reestruturação social da propriedade, pelo aumento do poder de decisão comunitária e pelo comprometimento existencial com as maiorias excluídas (CASANOVA, 2006b).

Ambos, Fals Borda e Casanova, fazem em suas obras uma leitura da realidade do desenvolvimento e da ciência desde a América Latina. Eles questionam o subdesenvolvimento e o papel da ciência na superação e na libertação dessa condição. A sociologia é o ponto de partida e a ciência comprometida se constrói ao longo de suas vidas e obras, como compromisso ético inescapável com as maiorias exploradas do subcontinente.

\title{
6 A "centralidade" do desenvolvimento e da região em Fals Borda e Casanova
}

A questão do desenvolvimento regional ocupa um lugar central nas obras de Fals Borda e Casanova. Eles construíram seus pensamentos e práticas ancorados nos problemas vividos no interior de seus países (região como espaço subnacional) e nos problemas comuns vividos pela América Latina (região como espaço supranacional/subcontinental).

1 Respeitado o ponto de vista de Pablo González Casanova a respeito da teoria da dependência, cabe notar que no interior desta se identificam enfoques que tomaram a sério a teoria do valor, sendo Ruy Mauro Marini reconhecido, inclusive, por ter aportado contribuição original com o conceito de superexploração. 
Nos textos analisados neste artigo (Es possible una sociología de la liberación? e Sociología de la explotación), as concepções de desenvolvimento e região estão presentes. O desenvolvimento em Fals Borda é tratado (no texto Es possible una sociologia de la liberación?) como condicionante do colonialismo intelectual. Combinado com a ciência universal e aplicado às realidades locais, este desenvolvimento deforma a cultura e aumenta a dependência (FALS BORDA, 1970). Fals Borda não se sentia à vontade para utilizar o termo desenvolvimento. Ele adotou o termo Kaziyadu, da língua huitoto, que significa amanhecer, despertar, como forma de expressar a resistência ao desenvolvimento e ao desenvolvimentismo: o amanhecer e o despertar dos povos (FALS BORDA, 2001).

O desenvolvimento em Casanova aparece como efeito da exploração. A origem do problema do desenvolvimento e sua solução passariam pela superação da ênfase no crescimento econômico e na consideração dos aspectos políticos e sociais. O desenvolvimento, para ele, é um fenômeno que deve ser analisado com métodos que permitam captar todas as suas dimensões, e não só a dimensão econômica (CASANOVA, 2013).

A concepção de região, para Fals Borda e Casanova, é a de espaço supranacional. Fals Borda e Casanova pensam com o desenvolvimento regional, corroborando a afirmação de que "cada região tem uma forma específica de produção e apropriação do conhecimento sobre si mesma" (MATTEDI, 2015, p. 72). Aqui entendemos a produção de ambos os autores como uma produção regional latino-americana, uma sociologia regional, nas palavras de Fals Borda (1970).

Como já foi mencionado, no texto selecionado para esse artigo (Es possible una sociología de la liberación?) Fals Borda não tratou da região como espaço subnacional, mas referindo-se à América Latina, como espaço continental. No livro Mompox y Loba, porém, publicado em 1979, a região assume a escala de espaço subnacional, articulando-se aí com o conceito de formação social:

\footnotetext{
Una formación social puede estudiarse como uma interacción de regiones vinculadas histórica y politicamente, que dejan de verse como entes solamente naturales e geográficos para recomponerse como entidades sociales y económicas dinâmicas que tienem una base espacial común. (FALS BORDA, 2002, p. 19A e B).
}

A hipótese de Fals Borda (2002) é do desenvolvimento desigual em nível regional devido a diferenças na velocidade de expansão do capitalismo. As diferenças que vêm, muitas vezes, desde a formação colonial, exigem tratamentos políticos especiais para cada nível.

Já Casanova trata da região como espaço subnacional no texto Sociología de la explotación, selecionado para esse artigo. Para ele existem dois tipos de exploração presentes em nosso tempo: a exploração de classes e a exploração de regiões. A exploração de classes é uma categoria que compreende formas de escravismo, feudalismo e capitalismo. Já a exploração de regiões engloba a exploração cidade-campo, a exploração colonial, a exploração imperialista e o colonialismo interno. A combinação das duas categorias é fonte de variação da sociedade capitalista e da exploração, considerando histórias distintas da clássica europeia (CASANOVA, 2006a). 
Fals Borda e Casanova problematizam o desenvolvimento na denúncia do colonialismo intelectual: no abandono do termo desenvolvimento e na adoção do Kaziyadu, para Fals Borda (2001); e na perspectiva do desenvolvimento inseparável da democracia, para Casanova (2006a). Quanto ao regional, reafirmam a necessidade de um pensamento e uma ação que deem conta das realidades subcontinental e sub-regional na América Latina.

\section{Considerações finais: desenvolvimento regional para libertar ou para explorar?}

É tempo de aprendermos a nos libertar do espelho eurocêntrico onde nossa imagem é sempre, necessariamente distorcida. É tempo, enfim, de deixar de ser o que não somos. (QUIJANO, 2005, p. 274).

A questão que dá título a este artigo é: Afinal, desenvolvimento regional serve para quê? Em resposta a essa questão trouxemos para a reflexão Orlando Fals Borda e Pablo González Casanova, Colômbia e México, respectivamente, mas, sobretudo, América Latina. O mapeamento proposto visou identificar elementos novos nessa sociologia-periferia e trazê-los para o debate, procurando incorporar contribuições não tão novas, antes desconhecidas, à teoria do desenvolvimento e à teoria do desenvolvimento regional.

Historicamente, a América Latina tem se "conformado" com o próprio subdesenvolvimento. Os vencedores, "de fora" e "de dentro", adotando a perspectiva do desenvolvimento, vêm reforçando a vitória alheia à custa dos eternos derrotados (THEIS, 2015). Fals Borda e Casanova denunciam essa conformação - o colonialismo intelectual, a ciência, o desenvolvimento - como parte do problema. Ela deforma e oculta os objetivos dos vencidos e favorece o encobrimento do Outro (CASANOVA, 2006b; FALS BORDA, 1970).

Por um lado, Fals Borda e Casanova denunciam o desenvolvimento regional eurocêntrico como instrumento de exploração. Por outro, contudo, enfatizam seu potencial de libertação. O desenvolvimento regional como libertação revela uma contradição entre a formação eurocêntrica dos cientistas sociais na América Latina e a necessidade de repensar - de fato, impensar - as ciências sociais no continente. Repensar é algo "normal", mas impensar implica romper com determinados parâmetros intelectuais, já que nem tudo pode ser explicado e compreendido a partir de alternativas disponíveis e questões já formuladas e consagradas, seja pela teoria social, seja pela teoria do desenvolvimento (TROUILLOT, 1995; WALLERSTEIN, 1999).

Um ponto evidenciado pelos dois autores aqui resenhados diz respeito ao compromisso do cientista com a práxis: ele precisa sair da torre de marfim do eurocentrismo e da academia e se comprometer, existencialmente, com as maiorias exploradas do subcontinente. Nesse sentido, há a necessidade de um conhecimento produzido regionalmente, de uma sociologia regional.

Ficam, não obstante, questões em aberto: Qual é o espaço que uma teoria social comprometida ocupa no debate sobre desenvolvimento regional? Qual é a responsabilidade que cabe aos cientistas sociais no questionamento e na superação do eurocentrismo presente tanto na ciência quanto no desenvolvimento regional praticados na América Latina? A sua teoria/prática científica demonstra o compromisso com as maiorias exploradas ou apenas reproduz a exploração? Fals 
Borda e Casanova oferecem boas pistas para essa reflexão. Mas, cabe ao leitor apropriar-se destes e de outros conhecimentos, a fim de repensar/impensar a teoria social, a teoria do desenvolvimento e o desenvolvimento regional - pensar $e$ impensar com a região - como seu compromisso ético-existencial.

\section{REFERÊNCIAS}

AMIN, Samir. El eurocentrismo: crítica de una ideología. México/DF: Siglo Veintiuno, 1989. Tradução de: Rosa Cusminsky de Cendrero.

BERTONCELO, Edison Ricardo Emiliano. Revisitando os Estudos do Desenvolvimento. $B I B, \mathrm{n}^{\circ} 71,1^{\circ}$ semestre de 2011, p. 95-122, 2011. Disponível em:

$<$ http://portal.anpocs.org/portal/index.php?option=com_docman\&task=cat_vie $w \&$ gid $=1139 \&$ Itemid $=435>$. Acesso em: 12 mai. 2015 .

BIELSCHOWSKY, Ricardo (org). Cinqüenta anos de pensamento da CEPAL. Rio de Janeiro: Record, p. 15-68, 2000.

BRESSER-PEREIRA, Luiz Carlos. As três interpretações da dependência. Perspectivas, São Paulo, v. 38, p. 17-48, jul./dez. 2010.

CARDOSO, F.H. As idéias e seu lugar. Ensaios sobre as teorias do desenvolvimento. Petrópolis, RJ: Vozes, 1993.

CASANOVA, Pablo González. Democracia no México. México: Ediciones Era, 2013. Edição Digital.

CASANOVA, Pablo González. Sociologia de la explotación. (Nueva edición corregida). Buenos Aires: Consejo Latinoamericano de Ciencias Sociales CLACSO, 2006a.

CASANOVA, Pablo González. As novas ciências e as humanidades: da academia à política. São Paulo: Boitempo Editorial, 2006b. Tradução de: Mouzar Benedito.

CHILCOTE, Ronad $\mathrm{H}$. Teorias reformistas e revolucionárias de desenvolvimento e subdesenvolvimento. Revista de Economia Política, Vol. 3, n 3, jul.-set., p. 103123, 1983.

DUSSEL, Enrique. 1492: o encobrimento do outro: a origem do mito da modernidade: conferências de Frankfurt. Petrópolis, RJ: Vozes, 1993. Tradução de: Jaime A. Clasen.

DUSSEL, Enrique. Ética da libertação na idade da globalização e da exclusão. $4^{\mathrm{a}}$ ed. Petrópolis, RJ: Vozes, 2012. Tradução de: Ephraim Ferreira Alves, Jaime A. Clasen, Lúcia M. E. Orth.

DUSSEL, Enrique. Filosofía de la liberación. Bogotá: Nueva América, 1996. Disponível

em: 
<http://bibliotecavirtual.clacso.org.ar/clacso/otros/20120227024607/filosofia.pd f>. Acesso em: 23 jan. 2015.

ESCOBAR, Arturo. La invención del Tercer Mundo. Construcción y desconstrucción del desarrollo. Caracas: Fundação Editorial Elperroy Larana, 2007.

ESTEVA, Gustavo. Desenvolvimento. In: SACHS, Wolfgang (org.). Dicionário do desenvolvimento: guia para o conhecimento como poder. Petrópolis: Vozes, 2000, p. 59-83. Tradução de: Vera Lucia M. Joscelyne, Susana de Gyalokay e Jaime A. Clasen.

FALS BORDA, Orlando. Mompox y loba. Historia doble de la Costa 1. 2 ed. Bogotá: El áncora Editores, 2002.

FALS BORDA, Orlando. Kaziyadu: registro del reciente despertar territorial en Colombia. Bogotá: Ediciones desde abajo, 2001. Disponível em: <http://www.sogeocol.edu.co/documentos/Okayi.pdf>. Acesso: 12 mai. 2016.

FALS BORDA, Orlando. Ciencia propia y colonialismo intelectual. México: Editorial nuestro tempo, 1970.

FARFÁN, Nicolás Armando Herrera; GUZMÁN, Lorena López (Comp.). Ciencia, compromisso y cambio social. Textos de Olando Fals Borda. $1^{\mathrm{a}}$ ed. Buenos Aires: El colectivo - Lanzas y Letras - Entensión Libros, 2012. Disponível em: $<$ http://bibliotecavirtual.clacso.org.ar/ar/libros/coedicion/fborda/fborda.pdf $>$.

Acesso em: 4 fev. 2015.

GERMANI, Gino. Textos de Gino Germani. In: MERA, Carolina; REBÓN, Julián (Coord.). Gino Germani, la sociedad en cuestión : antología comentada. $1^{\mathrm{a}}$ ed. Buenos Aires: Consejo Latinoamericano de Ciencias Sociales - CLACSO, 2010. Disponível

em: $<$ http://bibliotecavirtual.clacso.org.ar/ar/libros/coedicion/germani.pdf $>$. Acesso em: 2 maio 2015.

GOLDMANN, Lucien. Dialética e cultura. $2^{\mathrm{a}}$ ed. Rio de Janeiro: Paz e Terra, 1967. Traducao de: Luiz Fernando Cardoso, Carlos Nelson Coutinho e Giseh Vianna Konder.

LEÓN, Velia Cecilia Bobes. Sociología en América Latina: notas para una periodización. In: RODRÍGUEZ, Alaín Basail et al. (org.). Introducción a la sociología 3. Selección de lecturas. La Habana: Editorial Félix Varela, p. 322-349, 2004.

LOWY, Michael. Goldmann e o estruturalismo genético. Serv. Soc. Soc., São Paulo, n. 125, p. 24-40, abr. 2016. Disponível em $<$ http://www.scielo.br/scielo.php?script=sci_arttext\&pid=S010166282016000500024\&lng $=$ pt\&nrm=iso $>$. Acesso em 20 abr. 2016. DOI: http://dx.doi.org/10.1590/0101-6628.054. 
MATTEDI, Marcos Antônio. Pensando com o desenvolvimento regional: subsídios para um programa forte em desenvolvimento regional. Revista Brasileira de Desenvolvimento Regional, Blumenau, v. 2, n. 2, p. 059-105, june 2015. ISSN 2317-5443. Disponível em: <http://proxy.furb.br/ojs/index.php/rbdr/article/view/4807>. Acesso em: 23 abr. 2016. DOI: http://dx.doi.org/10.7867/2317-5443.2014v2n2p059-105.

OQUENDO, Luis J. González. Las ciencias sociales en América Latina: condiciones y particularidades. In: RODRÍGUEZ, Alaín Basail et al. (org.). Introducción a la sociología 3. Selección de lecturas. La Habana: Editorial Félix Varela, 2004, p. 362388.

PEET, Richard; HARTWICK, Elaine. Theories of development. Contentions, Arguments, Alternatives. $3^{\mathrm{a}}$ ed. New York: The Guilford Press, 2015.

QUIJANO, Aníbal. Colonialidade do poder, eurocentrismo e América Latina. In: LANDER, Edgardo (Org.). A colonialidade do saber. Eurocentrismo e ciências sociais. Perspectivas latino-americanas. $1^{\text {a }}$ ed. Buenos Aires: CLACSO, 2005, p. 227-278. Tradução de: Júlio César Casarin Barroso Silva.

QUIJANO, Aníbal. El fantasma del desarrollo en América Latina. Rev. Venez. De Econ. y Ciencias Sociales, 2000, vol. 6, n 2, p. 73-90.

ROSENMANN, Marcos Roitman (Comp.). De la sociología del poder a la sociología de la explotación: pensar América Latina en el siglo XXI / Pablo González Casanova. Bogotá: Siglo del Hombre Editores y Clacso, 2009.

THEIS, Ivo M. Territórios contestados e desenvolvimento desigual: perspectivas e desafios para a América Latina. In: E. Cecchetti y L. De Oliveira (orgs.), Territórios e desenvolvimentos contestados: diálogos, resistências e alternativas. Edifurb, p. 33-60, , Blumenau, Brasil, 2015.

TROUILLOT, Michel-Rolph. Silencing the past. Power and the production of history. Boston: Beacon Press, 1995.

WALLERSTEIN, Immanuel. Abrir las ciencias sociales. Mexico: Siglo XXI editores, 2006.

WALLERSTEIN, Immanuel. Impensar las ciências sociales. Los limites de los paradigmas decimonónicos. México; Espanha: Siglo Veintiuno editores, 1999. 
Submetido em 05/08/2016

Aprovado em 27/08/2016

\section{Sobre os autores}

Luciana Butzke

Doutora em Sociologia Política pela UFSC, professora da FURB, pesquisadora do Núcleo de Pesquisas em Desenvolvimento Regional, rua Antônio da Veiga, 140, Blumenau, Santa Catarina, lbutzke@furb.br

\section{Oklinger Mantovaneli Júnior}

Doutor em Sociologia UNESP, professor do PPGDR/FURB, pesquisador do Núcleo de Políticas Públicas/FURB.

E-mail: oklinger@furb.br.

Ivo Marcos Theis

Doutor em Geografia pela Universität Tübingen/Alemanha, professor do PPGDR/FURB, pesquisador do Núcleo de Pesquisas em Desenvolvimento Regional e professor do PPGDR/FURB.

E-mail: theis@furb.br. 